\title{
Reproductive Epidemiology in an Evolutionary Perspective: Why Bigger May Not Be Better
}

\author{
Olga Basso
}

Published online: 23 March 2014

(C) Springer International Publishing AG 2014

\begin{abstract}
Pregnancy and childbirth have been shaped by natural selection, and some reproductive endpoints, such as preterm birth and low birth weight, may be understood differently by considering our history. Mothers, whose very survival is threatened by pregnancy and childbirth, appear to play a crucial role in determining length of gestation and size of the baby. Having smaller babies may thus have conferred an advantage to mothers, despite the increased risk to individual offspring. Furthermore, it is unknown how much of the excess mortality risk of small and preterm babies is due to preterm birth and low birth weight per se, rather than to pathological factors that reduce birth weight and length of gestation. The apparently paradoxical phenomenon of intersecting mortality curves can be explained in this framework, which may shed a different light on these two central entities in perinatal epidemiology.
\end{abstract}

Keywords Reproductive epidemiology · Evolution · Maternal mortality $\cdot$ Infant mortality $\cdot$ Birth weight $\cdot$ Low birth weight $\cdot$ Length of gestation $\cdot$ Preterm birth

"Nothing in biology makes sense except in the light of evolution" goes the title of a famous essay by the geneticist and evolutionary biologist Dobzhansky [1]. Such a consideration seems particularly relevant when thinking about reproductive endpoints. Reproduction has been shaped by evolution-indeed, it is the mechanism through which evolution happens. Selective forces still exert a very strong influence during reproduction, as evidenced by the fact that nearly one-third of implanted embryos are lost before birth [2]. Given the complexity and potential for randomness of reproductive processes, it is not surprising that things would go wrong some of

\section{O. Basso $(\square)$}

Department of Obstetrics \& Gynecology and Department

of Epidemiology, Biostatistics, \& Occupational Health,

McGill University, Montreal, QC, Canada

e-mail: olga.basso@mcgill.ca the time. However, certain "adverse" reproductive outcomes may be the by-product of adaptations evolved through millennia of what can only be defined as a brutal history. Even in industrialized countries, where maternal and infant death rates have sharply declined in the last few decades, pregnancy and childbirth remain comparatively dangerous, and success in reducing the occurrence of certain complications, such as preterm birth and low birth weight, has been limited. A high proportion of infant deaths are ascribed to these conditions; yet, the evidence suggests that the mother plays a crucial role in determining both duration of gestation and size of the baby. Is it possible that the direct causal effect of preterm birth and low birth weight on infant morbidity and mortality is not as large as it appears? This article proposes some - personal and arguably speculative - considerations about why the persistence of these conditions may make sense in the light of evolution.

That reproduction exacts a high toll remains all too evident in developing countries. In 2011, maternal mortality was estimated to be 2.25 per 1,000 live births in developing countries, vs. 0.18 in industrialized ones. Early neonatal mortality was 17.7 and 2.6 per 1,000 live births in developing and industrialized countries, respectively [3]. Although maternal and child mortality throughout our history can only be guessed at, they were likely high. In ancient Rome, for example, rough (conservative) estimates suggest that there were 25 maternal deaths [4] and 300 infant deaths [4, 5], respectively, for every 1,000 live births, not dissimilar to 18th century England [4]. In 1920, maternal mortality varied widely among countries, with rates ranging from 2.42 per 1,000 in the Netherlands to 6.89 per 1,000 in the United States [6]. By 1960 , maternal mortality rates were down to 0.37 per 1,000 births in both countries [6].

The high mortality associated with pregnancy is in part due to the well-known difficulties of childbirth faced by humans. Among great apes, human birth is particularly challenging, and human babies are substantially more helpless (altricial) than those of our closest relatives. Indeed, it has been hypothesized that bipedalism and size of the fetal head have led to 
cutting pregnancy short in order to allow for "safe" passage through the birth canal (hence our so-called "secondary altriciality" at birth) [7-11], although another hypothesis suggests maternal metabolic constraints as the reason for limiting fetal growth and pregnancy duration [12]. Either way, there are objective limits to how large an infant - or how long a pregnancy - can be. Obstructed labor, which can also lead to hemorrhage and sepsis, remains a significant cause of maternal and perinatal mortality in developing countries [13-16]. This complication is especially prevalent where girls grow up with some degree of malnutrition and have children before achieving full pelvic growth [13], a set of circumstances that may have been relatively common at several stages during our history . The cost of producing large offspring, in terms of maternal resources, and the risks associated with giving birth when operative delivery was not an option, have likely resulted in the development of maternal mechanisms to limit fetal size. Haig [17] describes pregnancy as a conflict among genes from the mother, the father, and the fetus, each player having different stakes. Some disorders of pregnancy, such as gestational diabetes and preeclampsia, may have evolved from maternal attempts to limit fetal uptake of maternal resources and the resulting fetal responses to these attempts [17, 18].

In this perspective, it is then not surprising that maternal factors appear to be the most important determinants of fetal size, as suggested by the pattern of correlation of birth weight among siblings, very similar in full and maternal half siblings [19-21], and much lower in paternal half siblings [19], although the fathers' own size at birth predicts that of their babies [22-24]. A small study of babies conceived using donated eggs suggested that recipient's size had a greater influence on birth weight than donor's size [25]. Additionally, current evidence suggests that paternally expressed genes tend to favor uptake of maternal resources, while maternally expressed ones tend to limit it [26], as predicted by the parental-offspring conflict hypothesis [27]. Taken together, these observations support the notion that fetal growth is restricted primarily by the mother. Similarly, familial studies of preterm birth suggest transmission of this trait only through the female side $[28,29]$, which may indicate mitochondrial or imprinted genes (or, possibly, non-genetic transmission through the mother). In mammals, length of pregnancy has a substantial degree of natural variability, with humans tending towards the upper range, though it is unclear to what extent measurement error plays a role in these assessments [30].

The difficulties of childbirth have led to research into genes with accelerated evolution in humans as potential candidates for regulating timing of birth [11]. Identification of such genes would result in a leap in our understanding of the determinants of length of gestation, but the very survival of these genes to this day suggests that their contribution to the mortality of preterm babies may be limited. In a Norwegian sibling study, babies born early following a previous preterm birth had substantially lower perinatal mortality than babies born at the same gestation whose older sibling had been born at term [31]. These findings may indicate that preterm births among women predisposed to giving birth early are less frequently the result of pathological processes. It is thus not inconceivable that, throughout our history, non-pathological smallness (achieved through reduced fetal growth or shortening of gestation) may have conferred a modest excess risk to infants, while resulting in fewer casualties during childbirth. Although babies born full term (or large) would have better survival, selection typically operates by favoring maternal, rather than offspring, fitness [32]. Selection favoring the mother is hypothesized to be less pronounced in species with long postnatal care, where counter-strategies by the offspring are more likely to evolve [32], but death of the mother would, in and of itself, reduce the probability of her children surviving to reproductive age. A study of 19th century church records from seven Swedish parishes indicated that perinatal mortality of babies whose mother had died in childbirth was $28.4 \%$, and only $1.6 \%$ of the surviving orphans reached the age of five. A mother's death also affected her other young children; depending on whether they were less than one year old when their mother died, or between the ages of one and five, $3 \%$ and $13 \%$, respectively, survived to the age of 5 years [33]. While such a pattern may not be representative of other times and places, it can be safely assumed that motherless infants faced a grimmer future than their luckier counterparts.

Although it cannot be disputed that being small or premature is associated with high morbidity and mortality, we do not know the true extent of the causal contribution of birth weight and gestational age at birth on infant survival in a given population at a specific time, nor can it be estimated with modern causal inference methods [34, 35]. Babies are born early (or small) for a variety of reasons, many of which we don't know (or are unmeasured), and most of these pathways are pathological [36], likely conferring an extra risk to the infant, which cannot be disentangled from that caused by a reduction in gestational age (or size).

It is unclear whether smallness per se plays a causal role on infant survival [37], although a high surface-to-volume ratio compromises thermoregulation [38]. Nevertheless, birth weight of the parents, despite being correlated with that of their babies, does not appear to directly affect perinatal mortality [24]. The observed association between birth weight and mortality may thus in large part be due to pathologies that directly increase morbidity and mortality and simultaneously reduce birth weight. In theory, rare but strong unmeasured (and as yet unrecognized) factors could explain the entire gradient of mortality with birth weight, without the latter playing any causal role in risk [39]. A 2011 meta-analysis of studies of supplementation with multiple micronutrients during pregnancy [40] showed a $9 \%$ reduction in the prevalence of small-for-gestational age, but no benefit on mortality. On 
the contrary, in populations where the majority of births took place at home, the relative risk of neonatal mortality was higher in the intervention arm (1.47, $95 \%$ CI: 1.13, 1.92).

Reproductive epidemiologists are all too familiar with the apparently paradoxical phenomenon of intersecting mortality curves, whereby the neonatal mortality of a "high-risk" group of babies (e.g., babies of smokers [41], twins and triplets [42, 43]) is lower than that of the corresponding "low-risk group" at low birth weights or early gestations. A possible explanation for this pattern is that, given that a baby is born early (or small), babies in the "low" risk category have other, unmeasured, factors that collectively confer an overall higher mortality risk than the exposure being examined [43-49]. If so, the empirical rates would not represent the "true" risk due to being born at an early gestational week (or at a low birth weight), but would also include the additional risk conferred by the pathologies causing preterm birth or low birth weight.

Being born just one or two weeks early is associated with an increased risk of morbidity and mortality compared to term birth [50], but it is unclear how much of this risk is actually due to the timing of birth. Early-term births (at 37 and 38 weeks of gestation) have recently become a focus of attention and, in 2012, the American Journal of Obstetrics and Gynecology published a trio of articles on a new definition of the "preterm birth syndrome" [51-53], proposing that all births between 16 and 38 weeks be considered "preterm". However, if it can be hypothesized that "natural" (non-pathological) duration of gestation is normally distributed, for example with a mean of 280 days and a standard deviation of 10 days, $22.4 \%$ of babies would be born at 37-38 weeks (and $1.8 \%$ before 37 completed weeks). Thus, including early-term babies in the preterm category may result in classifying as pathological an overwhelming majority of births that are neither preventable nor caused by any pathology.

In fairness, the concern over early-term births has largely been aimed at reducing medical inductions without indication before 39 completed weeks of gestation, and such attention has resulted in stricter guidelines on when it is appropriate to induce. Some authors nevertheless wonder if excessive caution may now be exercised in determining whether an indication justifies delivery before 39 weeks, and worry that such guidelines fail to take into consideration the stillbirths that may be avoided by delivering babies earlier [54]. In a recent large registry study from the UK, induction without indication (as far as it could be ascertained) was associated with a lower risk of perinatal death at all weeks from 37 to 41, as well as with a lower rate of maternal hemorrhage at most weeks in the same range, compared with expectant management, the appropriate comparison to evaluate the impact of induction [55]. In addition, although prolonging gestation has long been the objective of clinical intervention, it is not fully clear that doing so results in improved neonatal outcome [56, 57].
In conclusion, although it is undeniable that both preterm birth and low birth weight are strongly associated with poor neonatal outcome, their direct causal role may be less than what is suggested by the observed risk, as the pathologies that result in a shorter gestation and disrupted fetal growth may play a major role $[37,39,43,45-47,49]$. When studying certain common reproductive endpoints, it is worth considering the possibility that they may have come to be as a result of the long and complex struggle between maternal and fetal genes. Mothers have a much larger influence than fathers on both birth weight and duration of gestation, which is in line with the notion that women have evolved mechanisms to maximize their own fitness, sometimes at the expense of individual offspring. Modern obstetrics, where widely available, has been extremely successful in making pregnancy and birth safer, but has not obliterated our history, and looking at our distant past when studying reproductive events may result in a new understanding of old problems.

Acknowledgements The author would like to thank the reviewer of this manuscript for providing constructive and helpful comments.

\section{Compliance with Ethics Guidelines}

Conflict of Interest $\mathrm{O}$ Basso declares no conflicts of interest.

Human and Animal Rights and Informed Consent This article does not contain any studies with human or animal subjects performed by any of the authors.

\section{References}

1. Dobzhansky T. Nothing in biology makes sense except in light of evolution. Am Biol Teach. 1973;35:125-9.

2. Wilcox AJ, Weinberg CR, O'Connor JF, Baird DD, et al. Incidence of early loss of pregnancy. N Engl J Med. 1988;319:189-94.

3. Lozano R, Wang H, Foreman KJ, Rajaratnam JK, et al. Progress towards Millennium Development Goals 4 and 5 on maternal and child mortality: an updated systematic analysis. Lancet. 2011;378: 1139-65.

4. Todman D. Childbirth in ancient Rome: from traditional folklore to obstetrics. Aust N Z J Obstet Gynaecol. 2007;47:82-5.

5. Volk T, Atkinson J. Is child death the crucible of evolution? J Soc Evol Cult Psychol. 2008;2:247-60.

6. Loudon I. The transformation of maternal mortality. BMJ. 1992;305: $1557-60$.

7. Rosenberg K, Trevathan W. Birth, obstetrics and human evolution. BJOG. 2002;109:1199-206.

8. Rosenberg KR, Trevathan WR. The evolution of human birth. Sci Am. 2001;285:72-7.

9. Steer P. Fetal growth. Br J Obstet Gynaecol. 1998;105:1133-5.

10. Steer PJ. Prematurity or immaturity? BJOG. 2006;113 Suppl 3:136-8.

11. Plunkett J, Doniger S, Orabona G, Morgan T, et al. An evolutionary genomic approach to identify genes involved in human birth timing. PLoS Genet. 2011;7:e1001365. 
12. Dunsworth HM, Warrener AG, Deacon T, Ellison PT, Pontzer H. Metabolic hypothesis for human altriciality. Proc Natl Acad Sci U S A. 2012;109:15212-6.

13. Wall LL. Obstetric vesicovaginal fistula as an international publichealth problem. Lancet. 2006;368:1201-9.

14. Alkire BC, Vincent JR, Burns CT, Metzler IS, et al. Obstructed labor and caesarean delivery: the cost and benefit of surgical intervention. PLoS One. 2012;7:e34595.

15. Dolea C, C A. Global burden of obstructed labour in the year 2000. In: Evidence and Information for policy (EIP). Geneva: World Health Organization; 2003.

16. Khan KS, Wojdyla D, Say L, Gulmezoglu AM, Van Look PF. WHO analysis of causes of maternal death: a systematic review. Lancet. 2006;367:1066-74.

17. Haig D. Genetic conflicts in human pregnancy. Q Rev Biol. 1993;68: 495-532.

18. Pijnenborg R, Vercruysse L, Hanssens M. Fetal-maternal conflict, trophoblast invasion, preeclampsia, and the red queen. Hypertens Pregnancy. 2008;27:183-96.

19. Morton NE. The inheritance of human birth weight. Ann Hum Genet. $1955 ; 20: 125-34$.

20. Basso O, Frydenberg M, Olsen SF, Olsen J. Two definitions of "small size at birth" as predictors of motor development at six months. Epidemiology. 2005; 16:657-63.

21. Lunde A, Melve KK, Gjessing HK, Skjaerven R, Irgens LM. Genetic and environmental influences on birth weight, birth length, head circumference, and gestational age by use of population-based parent-offspring data. Am J Epidemiol. 2007;165:734-41.

22. Klebanoff MA, Mednick BR, Schulsinger C, Secher NJ, Shiono PH. Father's effect on infant birth weight. Am J Obstet Gynecol. 1998;178:1022-6.

23. Magnus P, Gjessing HK, Skrondal A, Skjaerven R. Paternal contribution to birth weight. J Epidemiol Community Health. 2001;55:873-7.

24. Nordtveit TI, Melve KK, Skjaerven R. Mothers' and fathers' birth characteristics and perinatal mortality in their offspring: a populationbased cohort study. Paediatr Perinat Epidemiol. 2010;24:282-92.

25. Brooks AA, Johnson MR, Steer PJ, Pawson ME, Abdalla HI. Birth weight: nature or nurture? Early Hum Dev. 1995;42:29-35.

26. Piedrahita JA. The role of imprinted genes in fetal growth abnormalities. Birth Defects Res Part A Clin Mol Teratol. 2011;91:682-92.

27. Moore T, Haig D. Genomic imprinting in mammalian development — a parental tug-of-war. Trends Genet. 1991;7:45-9.

28. Wilcox AJ, Skjaerven R, Lie RT. Familial patterns of preterm delivery: maternal and fetal contributions. Am J Epidemiol. 2008;167:474-9.

29. Boyd HA, Poulsen G, Wohlfahrt J, Murray JC, et al. Maternal contributions to preterm delivery. Am J Epidemiol. 2009;170:1358-64.

30. Jukic AM, Baird DD, Weinberg CR, McConnaughey DR, Wilcox AJ. Length of human pregnancy and contributors to its natural variation. Hum Reprod. 2013;28:2848-55.

31. Melve KK, Skjaerven R, Gjessing HK, Oyen N. Recurrence of gestational age in sibships: implications for perinatal mortality. Am J Epidemiol. 1999;150:756-62.

32. Marshall DJ, Uller T. When is a maternal effect adaptive? Oikos. 2007;116:1957-63.

33. Hogberg U, Brostrom G. The demography of maternal mortality -7 swedish parishes in the 19th century. Int J Gynecol Obstet. 1985;23:489-97.

34. VanderWeele TJ, Hernandez-Diaz S. Is there a direct effect of preeclampsia on cerebral palsy not through preterm birth? Paediatr Perinat Epidemiol. 2011;25:111-5.
35. VanderWeele TJ, Mumford SL, Schisterman EF. Conditioning on intermediates in perinatal epidemiology. Epidemiology. 2012;23:1-9.

36. Greenwood C, Yudkin P, Sellers S, Impey L, Doyle P. Why is there a modifying effect of gestational age on risk factors for cerebral palsy? Arch Dis Child Fetal Neonatal Ed. 2005;90:F141-6.

37. Wilcox AJ. On the importance-and the unimportance-of birthweight. Int J Epidemiol. 2001;30:1233-41.

38. Narendran V, Hoath SB. Thermal management of the low birth weight infant: a cornerstone of neonatology. J Pediatr. 1999;134:529-31.

39. Basso O, Wilcox AJ, Weinberg CR. Birth weight and mortality: causality or confounding? Am J Epidemiol. 2006;164:303-11.

40. Haider BA, Yakoob MY, Bhutta ZA. Effect of multiple micronutrient supplementation during pregnancy on maternal and birth outcomes. BMC Public Health. 2011;11 Suppl 3:S19.

41. Yerushalmy J. Mother's cigarette smoking and survival of infant. Am J Obstet Gynecol. 1964;88:505-18.

42. Lie RT. Invited commentary: intersecting perinatal mortality curves by gestational age-are appearances deceiving? Am J Epidemiol. 2000;152:1117-9. discussion 1120.

43. Basso O, Wilcox A. Mortality risk among preterm babies: immaturity versus underlying pathology. Epidemiology. 2010;21:521-7.

44. Wilcox AJ, Weinberg CR, Basso O. On the pitfalls of adjusting for gestational age at birth. Am J Epidemiol. 2011;174:1062-8.

45. Basso O, Wilcox AJ. Might rare factors account for most of the mortality of preterm babies? Epidemiology. 2011;22:320-7.

46. Basso O, Wilcox AJ. Intersecting birth weight-specific mortality curves: solving the riddle. Am J Epidemiol. 2009;169:787-97.

47. Whitcomb BW, Schisterman EF, Perkins NJ, Platt RW. Quantification of collider-stratification bias and the birthweight paradox. Paediatr Perinat Epidemiol. 2009;23:394-402.

48. Schisterman EF, Whitcomb BW, Mumford SL, Platt RW. Z-scores and the birthweight paradox. Paediatr Perinat Epidemiol. 2009;23:403-13.

49. Hernandez-Diaz S, Schisterman EF, Hernan MA. The birth weight "paradox" uncovered? Am J Epidemiol. 2006;164:1115-20.

50. Gyamfi-Bannerman C. The scope of the problem: the epidemiology of late preterm and early-term birth. Semin Perinatol. 2011;35:246-8.

51. Goldenberg RL, Gravett MG, Iams J, Papageorghiou AT, et al. The preterm birth syndrome: issues to consider in creating a classification system. Am J Obstet Gynecol. 2012;206:113-8.

52. Kramer MS, Papageorghiou A, Culhane J, Bhutta Z, et al. Challenges in defining and classifying the preterm birth syndrome. Am J Obstet Gynecol. 2012;206:108-12.

53. Villar J, Papageorghiou AT, Knight HE, Gravett MG, et al. The preterm birth syndrome: a prototype phenotypic classification. Am J Obstet Gynecol. 2012;206:119-23.

54. Norwitz ER, Greenberg JA. Prevention of early-term deliveries: much ado about nothing? Rev Obstet Gynecol. 2013;6:43-5.

55. Stock SJ, Ferguson E, Duffy A, Ford I, et al. Outcomes of elective induction of labour compared with expectant management: population based study. BMJ. 2012;344:e2838.

56. Alfirevic Z. Tocolytics: do they actually work? BMJ. 2012;345: e6531.

57. Haas DM, Caldwell DM, Kirkpatrick P, McIntosh JJ, Welton NJ. Tocolytic therapy for preterm delivery: systematic review and network meta-analysis. BMJ. 2012;345:e6226. 